This is the peer reviewed version of the following article: Tuomisto S, Koivula M, Åstedt-Kurki P, Helminen M. (2018) Family involvement in rehabilitation: Coronary artery disease-patients' perspectives, which has been published in final form at Journal of Clinical Nursing, 2018, 27(15-16), 3020-3031. https://doi.org/10.1111/jocn.14494. This article may be used for non-commercial purposes in accordance with Wiley Terms and Conditions for Use of Self-Archived Versions.

\title{
Family Involvement in Rehabilitation: Coronary Artery Disease-patients' perspectives
}

\section{ABSTRACT}

Aims and objectives: The aim of this paper is to describe CAD -patients' perceptions of family involvement in rehabilitation and the connection between background factors and family involvement. Background: CAD-patients hospital stays can be very concise. Family members can support rehabilitation, but many challenges can emerge. There is a need to nurture patients and family members in an individual way and to recognize their concerns. More accurate patient education should be available for patients and their family members.

Design: This study is a descriptive cross-sectional study.

Methods: Data were collected from CAD- patients at least six weeks after discharge from hospital $(n=169)$ with a postal questionnaire. The Family Involvement in Rehabilitation (FIRE) -scale measures family members' promotion of patients' rehabilitation and issues encumbering rehabilitation in family. The data has been analysed with statistical methods. Both parametric and non-parametric tests were used to evaluate group differences.

Results: CAD-patients perceived that family promotes their rehabilitation significantly. Respondents also perceived challenges at home. Family relations before hospitalisation were related to all sub-areas of family promoting rehabilitation and one sub-area of issues encumbering rehabilitation in family. Patients with symptoms at rest also had more encumberance on their rehabilitation. Patients who had undergone coronary artery bypass surgery perceived more challenges than PCI (Percutaneous Coronary Intervention) -patients in many sub-areas of issues encumbering rehabilitation in family.

Conclusions: Family relations prior to illness and the rigor of heart symptoms are significantly relevant to challenges that can occur between patient and their family members.

Relevance to clinical practice: Health care staff need to pay attention to CAD-patients' invidual situation and patient education should be more family-centered. In the future, it would be noteworthy 
to collect more data from family members of CAD patients and to find out their perceptions of family involvement.

What does this paper contribute to the wider global clinical community?

- This paper advances the understanding of family involvement in CAD-patients' rehabilitation

- The meaning of family relations and the severity of patients' heart symptoms must be taken into account as a factor affecting rehabilitation after hospital discharge

\section{Keywords}

Coronary Artery Disease patient, Family, Involvement, Nursing, Rehabilitation

\section{INTRODUCTION}

Cardiovascular diseases are the major cause of death worldwide (World Health Organization, 2016). The realization of heart rehabilitation has changed during the last thirty years simultaneously with the development of new medicine for cardiovascular diseases (Kraus \& Keteyian, 2007; Rolley \& Thompson, 2012). For the most part cardiac rehabilitation is organized by the municipal health care system and heart associations. In Finland, also The Social Insurance Institution of Finland KELA (2017) is a significant organizer of rehabilitation. Cardiac rehabilitation programs aim to enhance patients' physical and psychosocial functioning, and prevent additional cardiovascular problems. The three most important parts of cardiac rehabilitation are exercise guidance and training, healthy life style and counseling to reduce stress. (American Heart Association, 2017; Janssen, De Gucht, van Exel \& Maas, 2012). 
Assessment of psychosocial factors, such as low socio-economic status, deficiency of social support, stress at work and in family life, hatred, depression, anxiety and other mental disorders, can help recognize possible impediments to lifestyle changes and adhesion to medication (Piepoli et al. 2016).

CAD can cause substantial difficulties in physical function. The prevention of later cardiovascular events and preserving physical performance are major challenges in preventive care. (Ades, 2001.) More individual and customized rehabilitation is needed especially for elderly cardiac patients (Dolansky \& Moore, 2008). Currently the length of hospital stay for coronary artery disease (CAD) patients shortens all the time. A patient who has undergone Percutaneous Coronary Intervention (PCI), for example, can be discharged from the hospital in a few days. This endangers good interaction and collaboration not only with patients but also with their family members and caregivers. Because of this, health care staff have more limited opportunities to influence patients' health behaviours. (Rolley \& Thompson, 2012.) Nurses consider family as an important part of patients' care, but negative attitudes towards family involvement exist. More information and education for health care staff is needed on this issue. (Luttik et al., 2017.) There is a need to support patients and family members in a tailored way, taking into account their concerns. Patient and spouses can have different priorities concerning rehabilitation and pursuing the health care advices can become more difficult. (Kärner Köhler, Nilsson, Jaarsma \& Tingström, 2017.) An efficient way to promote cardiovascular health is to regard family-based approaches that target family members, advance communication in the family unit and take into consideration the invidual circumstances of families (Vedanthan, et al., 2016). It is very important to develop models that health care professionals can use when working with families in different sub-areas of health care (Lukkarinen \& Kyngäs, 2003; Bell \& Wright, 2011). In this study, rehabilitation means the phase when a patient is recovering at home. 
Involvement is a very diverse and dynamic concept (Entwistle \& Watt, 2006; Olding et al., 2016) and it can be positive or negative (Arnetz J, Zhdanova \& Arnetz B., 2016). Besides activities and social interactions, involvement includes the thoughts, feelings and meanings that person has. Involvement has various aspects and can be seen, for example, as getting caught up in an activity, being affected by an activity and feeling involved. (Entwistle \& Watt, 2006.) There are also many involvement-related concepts such as participation (Olding et al., 2016) which can be seen as a group of values and may include for example active engagement, free choice, opportunities, having an impact, inclusion and different kind of responsibilities (Hammel et al., 2008). In practical terms these concepts are often used inconsistently. In this article family involvement refers to the different ways that family members partake or engage in patients rehabilitation and it includes both positive and negative perspectives. These two standpoints are named family promoting rehabilitation and issues encumbering rehabilitation in family.

\section{BACKGROUND}

Often family caregivers provide emotional and practical support for patients, but also can take part in decision-making (DuBenske et al., 2010). The importance of paying attention to the family perspective when planning rehabilitation is highlighted (Dalteg, Benzein, Fridlund \& Malm, 2011; Kärner, Dahlgren \& Bergdahl, 2004). Earlier studies indicate that family members and relatives are the best social support for patients awaiting coronary artery bypass grafting (Koivula, Paunonen-Ilmonen, Tarkka MT, Tarkka M \& Laippala, 2002; Rantanen et al., 2008). Patients experience that the support received from family and friends and sharing experiences with other patients during cardiac rehabilitation effects on the quality 
of their recovery (Pryor, Page, Patsamanis \& Jolly, 2013). Spouses' optimism and positive attitudes towards lifestyle changes are ideal circumstances for recovery (Kärner et al., 2004).

Family members can involve themselves many ways in the rehabilitation process. They can promote patients' rehabilitation, but several challenges may occur (Dalteg et al., 2011; Knoll \& Johnson, 2000; Mahrer-Imhof, Hoffmann \& Froelicher, 2007; Stewart, Davidson, Meade, Hirth \& Makrides, 2000). Earlier studies show that defective planning of CADpatients ${ }^{\prime}$ treatment and rehabilitation causes insecurity, because patients do not have a proper treatment plan or sufficient patient education (Lukkarinen \& Kyngäs, 2003; Lie, Bunch, Smeby, Arnesen \& Hamilton, 2012). Spouses disclose the lack of support from health care staff and sometimes must support the whole family in the illness and rehabilitation process (Lukkarinen \& Kyngäs, 2003; Stewart et al.2000). Family members can feel stressed about the responsibility of taking care of the patient and managing daily routines. Changes in domestic roles and concerns about their family's economic situation can also increase encumberance. (Lukkarinen \& Kyngäs, 2003; Stewart et al., 2000.) Patients and spouses can identify the deficiency of communication and expressing emotions (Dalteg et al., 2011). Nonempathetic attitudes and the inability to be supportive are also a reality for some families (Kärner et al.,2004) and patients may recognise the lack of understanding and support from their spouses (Benyamini, Medalion \& Garfinkel, 2007; Kärner et al.,2004; Stewart et al., 2000). Many CAD -patients' and their spouses have also had concerns about their sex life (Dalteg et al., 2011; Koivula et al., 2002; Lukkarinen \& Kyngäs, 2003; Rantanen et al., 2008). More accurate patient education should be available to facilitate the patients' rehabilitation. Also a link to the hospital would be important if complications occur. (Lie et al., 2012.) This study sought to measure also the challenges that exist during rehabilitation at home, so that patient education could be developed and better targeted to relevant issues. 


\section{METHODS}

\section{Aims}

The aim of this paper is to describe CAD -patients' perceptions of family involvement in rehabilitation and the connection between background factors and family involvement.

The research questions were as follows:

1. How do CAD - patients perceive family members promoting rehabilitation?

2. How do CAD-patients perceive encumberance in rehabilitation among family members?

3. How are background variables connected to family involvement in CAD -patients“ rehabilitation?

\section{Design and sample}

This study is a descriptive cross-sectional study and convenience sampling was used. The sample comprised of coronary artery disease patients who have been undergoing hospital treatment and gave an informed consent. Patients, who did not have coronary artery disease, do not speak Finnish or for some reason are not capable to answer a questionnaire, were excluded. Patients may not have been able to answer because of factors such as poor health condition, poor vision, or serious mental health problems. Patients who have no family members were also excluded. 


\section{Data collection}

Data for this study were collected through postal questionnaires from CAD patients at least six weeks or more after discharge from the hospital, by which time patients had already experienced rehabilitation at home. Data were collected in one university hospital in Southern Finland. The participants were recruited from an information group targeted to CAD patients. The voluntary information group organized by the hospital convenes once and session consists of lectures given by different professionals: a cardiologist, a nutritionist, a physiotherapist and a rehabilitation nurse. Patients can participate alone or with a family member. Besides the information group, participants were recruited also from cardiac wards. The patients' informed consent was requested when they got verbal and written information about the study, and those who agreed to participate signed the consent. For the most part, data collection was done by the first author, but nursing staff in the cardiac wards assisted.

Sample size estimate $(n=189)$ produced by power analysis, using results from a pilot study (Tuomisto, Koivula \& Joronen, 2014), was calculated by a statistician as follows: the standard deviation of 0.7 is calculated from the Family promoting rehabilitation- and Issues encumbering rehabilitation in family -subscales. To be able to estimate the sample size, the mean sumscore value with $95 \%$ confidence interval and a marginal error no more than 0.1 was used. The sample size calculation was performed and the suitable sample size is 189 respondents (Levy \& Lemeshow, 1991). When the non-response rate of 15 percent in the preliminary study is taken into account, the final sample size needed results into 218.Informed consent was collected from these 218 patients when they participated in the group session or were discharged from the hospital. A structured questionnaire was sent to patients by mail and 172 patients filled it out, yielding a 79 percent response rate; three questionnaires were rejected because of missing answers $(n=169)$. Data collection was carried out between 2013 and 2015 . 


\section{Instruments}

The Family Involvement in Rehabilitation (FIRE) -questionnaire was designed for this study, and it started with a literature review and inductive content analysis. The results of the analysis were applied to form the items and subscales for the FIRE -questionnaire. In addition to the essential background information (17 questions) which are presented in Table I, the questionnaire contains two parts: Family promoting rehabilitation (16 items) and Issues encumbering rehabilitation in family (30 items).

Family promoting rehabilitation consists of four sub-scales: enabling good circumstances ( 4 items), family closeness (4 items), a family member as a carer (4 items), and motivating patient (4 items). This part was measured with the following items, among others: My family helps me with daily chores; My family takes care of me; My family seeks information about my illness; My family members have positive attitude to my recovery; and My family supports me with decision-making concerning treatment.

Issues encumbering rehabilitation in family describes the challenges that can emerge at home. This part contains six sub-scales; future uncertainty (4 items), inadequate support from nursing staff (4 items), processing emotions (4 items), the familys' coping with everyday life (9 items), family interaction (5 items) and family responsibilities for the patient (4 items). Examples of the items in this part: Lifestyle changes cause negative reactions in our family; Support from health care staff is deficient; My illness causes anxiety and fear for my family members; and Misunderstandings cause trouble between family members. A pilot study was performed to test the questionnaire (Tuomisto et al., 2014), and it showed that the questions were understandable to patients and that the preliminary internal consistency and concurrent validity were fairly good. 
Items were measured on a 6-point Likert-scale (1=strongly disagree; 2=disagree; $3=$ slightly disagree; $4=$ slightly agree; $5=$ agree; $6=$ strongly agree). The reliability of the FIRE scale was evaluated using Cronbach's alpha coefficient; the values ranged from $0.681-0.933$ (Table II.). The content validity of the FIRE scale is based on the literature (Benyamini et al., 2007; Dalteg et al., 2011; Knoll \& Johnson, 2000; Kärner et al., 2004; Mahrer-Imhof et al., 2007; Murray, O'Farrel, \& Huston, 2000; Rantanen et al., 2008; Stewart et al., 2000). Concurrent validity with FAFHES (Family Functioning, Health and Social support) instrument was good in pilot study (Tuomisto et al., 2014). FAFHES-questionnaire is a valid instrument measuring family functioning, family health and social support in family and it is used for exploration of heart patients and their family members (Åstedt-Kurki, Tarkka, Paavilainen \& Lehti, 2002).

\section{Ethical considerations}

The hospital ethics committee gave a favourable statement, and the administrators of the clinic granted permission to implement the study (Rebar, Gersch, Macnee, \& McCabe, 2011). Based on the preliminary study, power analysis was conducted for calculating a minimum of the needed respondents. During recruitment, it was underlined that a patient can refuse to attend or may terminate at any time, and if any questions would arise, they could contact the researcher. Patients were also informed about confidentiality of personal data. The signed consents and questionnaires were coded if a new questionnaire needed to be sent, and anonymity was controlled throughout all the stages of the study (World Medical Association, 2017). 


\section{Data analysis}

Some of the background variables were recategorised in order to facilitate analysis. Age was categorised in three groups: 60 years or less; $61-74$ years; and 75 years or more. Marital status originally contained six options: married, cohabiting, in registered partnership, single, divorced and widowed. Because there were such small groups, it was narrowed down to three groups: married, cohabiting, or without a relationship. Spouses' working status was categorised as either working or not working. A third option, retired, was combined with the not working group. Family relations before hospitalisation were originally categorised as 1) close, 2) quite close, 3) not particularly close, or 4) our relationship has been bad. Groups 3 and 4 were combined into a not close relationship. The last background variable that was recategorised was economic situation which was assorted also to three groups: meager; moderate; and good/excellent. Originally, there was also a fourth group, excellent, but it was later combined with group 3.

Demographic characteristics were described by frequencies and percentages. Means and standard deviations were used to describe subscales that were normally distributed. Parametric tests, an independent samples t-test and a one-way ANOVA, were used to compare mean differences between groups. Medians and quartiles (Tukey's Hinges), were calculated to describe the subscales that were not normally distributed. The differences between groups were compared by using non-parametric tests: a Kruskal-Wallis test and a Mann-Whitney U-test. A $P$-value of $<0.05$ was considered as significant (Munro, 2005). Data was analysed using the SPSS (Statistical Package for Social Sciences) Statistics for Windows version 22 -program (IBM Corp., Armonk, NY, USA). 


\section{RESULTS}

\section{Descriptive characteristics}

Most of the participants (76\%) were men. More than half (55\%) the patients were aged 61-74 years. The majority (83\%) were married, and most of the spouses $(70 \%)$ were not working. A preponderance of patients $(74 \%)$ assessed they had a close relationship with their family members, and over half $(51 \%)$ the patients defined themselves as having moderate economic status before hospitalisation (Table I).

\section{Patients' history of coronary artery disease (CAD)}

Almost half the patients (49\%) had received diagnoses within two years. One-third of the patients (33\%) did not experience chest pain, even at rest; a quarter $(25 \%)$ had chest pain with heavy exertion and 15 percent also at rest. Most patients $(61 \%)$ had previously been treated in hospital from one to 20 times because of chest pain, with an average of two times. Nearly half $(43 \%)$ the patients had suffered myocardial infarction, a small number of the participants (13\%) had thrombolytic therapy, and a majority had gone through angiography (96\%). PCI was performed on 75 percent and CABG (coronary artery bypass grafting) to 11 percent of the patients (Table I).

PLEASE INSERT TABLE I HERE

PLEASE INSERT TABLE II HERE

Family promoting rehabilitation and connections to background variables 
To describe the Family promoting rehabilitation -sub-scale, it was divided into three sections: minor (range 16-42, 2\%) mediocre (range 43-69, 9\%) and significant (range 70-96, 89\%). Patients perceived that family members gave a significant contribution to their rehabilitation (mean 81.3, SD 11.9) (Table II).

The background variables that were statistically significantly associated with family involvement are reported in this section. Family relations were associated with family promoting rehabilitation $(\mathrm{p}<.001)$ such that patients who had close family relationships $(\mathrm{Md}$ 85.0, Q1 79.0, Q3 91.5) assessed that family members promote their rehabilitation more than those who described their family relations as quite close (Md 79.0, Q1 72.0, Q3 82.0) or not close (Md 75.0, Q1 44.0, Q3 79.0). Myocardial infarction was also related to family promoting rehabilitation ( $\mathrm{p}=.038)$. Patients who had suffered myocardial infarction (Md 83.0, Q1 79.0, Q3 91.0) assessed that family members promote their rehabilitation more than those who had not endured the condition (Md 80.5, Q1 75.0, Q3 88.0) (data not shown in Tables).

Patients who lived in cohabitation had higher values in the enabling good circumstances -subscale than those who were married or without a relationship. Family relations before hospitalisation were related to all dimensions of family promoting rehabilitation. Patients who had a close relationship with their family members had good circumstances, closeness, a family member as a carer, and family motivating them more often than those who did not have close relationships with family members (Table III). PCI was associated with family motivating the patient ( $\mathrm{p}=.030)$ : those who had undergone PCI (Md 21.0, Q1 20.0, Q3 23.0) had been motivated more by family than those who had not been treated with PCI (Md 20.0, Q1 16.0, Q3 23.0).

\section{PLEASE INSERT TABLE III HERE}




\section{Issues encumbering rehabilitation in family and connections to background variables}

The issues encumbering rehabilitation in family -subscale was also distributed: minor encumberance (range 30-80, 47\%), mediocre encumberance (81-130, 50\%), and significant encumberance (131-180, 3\%). Patients perceived mediocre encumberance among family members in the rehabilitation process (mean 82.5, SD 22.9) (Table II).

Family relations before illness were associated with encumbering rehabilitation. Those who did not have close relationships with family members before illness (mean 106.8, SD 25.4) had more of an encumberance on their rehabilitation $(\mathrm{p}=.013)$. The appearance of heart symptoms was also related to encumberance such that patients with symptoms at rest (mean 92.4, SD 20.1) also had more encumberance on their rehabilitation $(\mathrm{p}=.033)$. Those who had not undergone PCI (mean 96.5, SD 22.0) had more challenges in rehabilitation than those who were treated with PCI (mean 77.5, SD 21.3, $\mathrm{p}<.001)$. CABG was also associated $(\mathrm{p}=.005)$ with issues encumbering rehabilitation such that those who had undergone CABG had more encumberance (mean 98.8, SD 26.4) than those who had not undergone the operation (80.6, SD 21.7) (Data not shown in Tables).

Gender was associated with processing emotions, family interaction, and family responsibilities for the patient, and men experienced more challenges in these areas. Marital status was related to processing emotions and family responsibilities for the patient, so patients who lived in cohabitation experienced more difficulties in these areas. Family relations were associated with family interaction, and those with close family relations before hospitalisation had less challenges in this area (Table IVa).

The onset of heart symptoms was related to the family's coping with everyday life and family interaction such that patients who had been suffering from heart symptoms for a longer time had more difficulties. The patients who experienced chest pain more easily also 
experienced more challenges in the family's coping with everyday life. If a patient had been treated in hospital because of chest pain, he or she experienced more inconveniences in emotional processing. Patients who had undergone PCI had the fewest challenges in all of the subdivisions: future uncertainty, inadequate support from nursing staff, processing emotions, the family's coping with everyday life, family interaction, and family responsibilities for the patient. Those who had undergone $\mathrm{CABG}$, experienced more encumbering issues in future uncertainty, inadequate support from nursing staff, processing emotions, family interaction and family responsibilities for the patient than those who had not undergone CABG. (Table IV b.)

\section{PLEASE INSERT TABLE IVa HERE}

PLEASE INSERT TABLE IVb HERE

\section{DISCUSSION}

\section{Review of the results}

Results of this study demonstrate that most patients considered their family members as an asset in their rehabilitation to a great extent. The closeness between family members in general was considered very good. Family relations before hospitalisation were related to all sub-areas of family promoting rehabilitation and one sub-area of issues encumbering rehabilitation in family. The meaning of closeness between family members has also been highlighted in several earlier studies (Dalteg et al., 2011; Hagan, Botti, \& Watts, 2007; Knoll \& Johnson, 2000; Koivula et al., 2002; Salminen-Tuomaala, 2013). Many studies indicate that spouses' positive attitude, optimism, and empathic approach are meaningful in patients' recovery (Lukkarinen \& Kyngäs, 2003; Kärner et al., 2004; Stewart et al., 2000; Eriksson, 
Asplund, \& Svedlund, 2010; Åstedt-Kurki, Lehti, Tarkka \& Paavilainen, 2004). Our results highlight that good family relations promote CAD patients' rehabilitation, and poor family relations encumber it.

Respondents perceived some issues encumbering rehabilitation at home. Most challenges were caused by everyday life and included factors such as economic worries, concerns about family members' coping, and domestic roles. Patients who had been suffering from heart symptoms for a longer time had more difficulties with everyday life and interaction between family members. In earlier studies, the same types of results were also found, indicating that the need to change domestic roles or share chores differently can cause problems (Lukkarinen \& Kyngäs, 2003; Stewart et al., 2000). This study demonstrates that patients who experienced chest pain more easily had more challenges in the family's coping with everyday life. Other studies show parallel results: the greater the effect of the illness on the patient's daily life, the worse the family health (Åstedt-Kurki et al., 2002). Patients who had undergone coronary artery bypass surgery (11\% of respondents) perceived more challenges than PCI patients in future uncertainty, inadequate support from nursing staff, in processing emotions, in family interaction, and in family responsibilities for the patients. Insufficient information about the patient's illness can cause insecurity in family (Knoll \& Johnson, 2000). Family members can have negative attitudes and feelings towards changes caused by the illness of a family member, and sometimes it is because they lack knowledge (Knoll \& Johnson, 2000; Kärner et al., 2004). It has been found that informing and educating older patients and their family members is insufficient (Palonen, 2016). Family members who receive relevant information can prepare to deal with challenges and uncertainty (Roohafza et al., 2015). Especially families of CABG patients need rich support from health care staff. PCI -patients perceive fewer challenges and gain strength easier after the operation, which might create an illusion of full recovery. Still, CAD is a prominent part of patients' and their family members' 
lives, and these perspectives should be taken into consideration when patients are being discharged from hospital.

In this study, no statistically significant differences were found between age and family involvement. The incidence of CAD has decreased among people of working age and has become more an illness of the elderly (Finnish Heart Association, 2017). In this study, the mean age of the respondents was 67 years. Most patients who suffer from CAD are elderly, and that can induce certain stipulations for rehabilitation. Earlier studies have found, for example, that reversion to earlier levels of physical function can be slower (Dolansky \& Moore, 2007) and that home-based rehabilitation programmes may be specifically useful among older CAD patients who benefit most from cardiac rehabilitation (Shepherd \& While, 2012).

The description, intensity, and location of heart symptoms were found to be genderspecific (Ghezeljeh et al., 2010). Regarding gender differences, the majority of respondents in this study $(76 \%)$ were men. In general, they experienced more challenges in family interaction, in processing emotions, and with family responsibilities. It might be that men are more reserved when opening up with their emotions and would need more encouragement to talk about these issues. This would be intrinsic to acknowledge in the dialogue between the health care staff and the patient.

This study adduced that communication problems, sharing responsibilities, dealing with different emotions and a wide range of issues can cause challenges between patients and their family members in the rehabilitation process after hospital discharge. All these challenges are meaningful and have tremendous signification to patients recovery. 


\section{Reliability of the study}

In the hospital where this study was implemented, the number of hospitalisations attributable to CAD was 3677 in the year 2014 (National Institute for Health and Welfare, 2015). The hospital district serves over half a million residents from 23 municipalities. It is important that the research sample is wide-ranging and large enough to represent the population group in the best possible way. Informed consent was collected from 218 patients. The response rate was good (79\%), and most of the questionnaires were filled conscientiously. There is a possibility that selection bias affected the study results because the patients who were transferred to follow-up care at other hospitals or whose condition was weak were not asked to participate. All possible participants were not reached due to challenges in data collection. Data accrued slowly from the cardiac wards because the researcher was not able to be present every day and the nursing staff in the busy ward did not have time to recruit all the patients. In this study, only 24 percent of the respondents were women, but this number can be seen as representative because other Finnish studies have demonstrated equal percentages (Rantanen et al., 2008; Roos, 2012). Data can be seen as quite comprehensive because patients who took part in this study, had very different backgrounds. Some patients had been suffering from CAD for many years, and some had been diagnosed recently. Others had undergone surgery or coronary angioplasty, and the stages of the illness can be diverse. A more accurate nonresponse analysis was not possible because not enough profound information was collected about patients who refused.

Family involvement consists of two different aspects: family promoting rehabilitation and issues encumbering rehabilitation in family (Benyamini et al., 2007; Dalteg et al., 2011; Knoll \& Johnson, 2000; Kärner et al., 2004; Mahrer-Imhof et al., 2007; Murray, O’Farrel, \& Huston, 2000; Rantanen et al., 2008; Stewart et al., 2000). Because encumberance or challenges 
in rehabilitation must be recognised, the FIRE scale was developed for this study to measure the two aspects. Cronbach's alpha coefficients proved that the reliability of the FIRE scale can be considered good (values between 0.681-0.933). The questionnaire was apprehensible to patients, and returned questionnaires contained only a few missing answers. The answers were divided mainly throughout the Likert-scale. With regard to background variables, some groups were very small, which influences the reliability. The psychometric properties of the FIRE scale will be tested more extensively in the future (DeVellis, 2012).

\section{CONCLUSION}

The conclusion of this study is that family members have an essential role in coronary artery disease patients' rehabilitation, but they are also involved with issues encumbering rehabilitation. Especially poor family relations and severity of the disease have significant effects on issues that can cause encumberance during the patients' rehabilitation at home. The results of this study confirm the need to develop family nursing. With appropriate information and support from health care staff to family members, many challenges could be avoided or alleviated.

\section{RELEVANCE TO CLINICAL PRACTICE}

Health care staff need to address issues concerning family relations and the possible discomforts between family members and the patient before they are discharged from hospital. Health care staff should also recognise that patients who have persistent heart symptoms, are more likely to have challenges in rehabilitation at home and may need more counselling and support. A very substantial issue is also to regard other family members in addition to the 
spouse. In the future, it would be important to collect more data from family members of CAD patients and to find out their appraisal of family involvement. 


\section{REFERENCES}

Ades, P. A. (2001). Cardiac rehabilitation and secondary prevention of coronary heart disease. New England Journal of Medicine, 345, 892-902.

American Heart Association. 2017. Cardiac Rehabilitation. Retrieved from: http://www.heart.org/HEARTORG/Conditions/More/CardiacRehab/CardiacRehab_UCM_002079_SubHomePage.jsp Accessed 29 August 2017.

Arnetz, J. E., Zhdanova, L., \& Arnetz, B. B. (2016). Patient involvement: A new source of stress in health care work? Health Communication, 31, 1566-1572.

Bell, J. M., \& Wright, L. M. (2011). The illness beliefs model creating practice knowledge in family systems nursing for families experiencing illness. In E. K. Svavarsdottir \& H. Jonsdottir (Eds.), Family nursing in action. University of Iceland Press, Reykjavik.

Benyamini, Y., Medalion, B., \& Garfinkel, D. (2007). Patient and spouse perceptions of the patient's heart disease and their associations with received and provided social support and undermining. Psychology \& Health, 22, 765-785.

Dalteg, T., Benzein, E., Fridlund, B., \& Malm, E. (2011). Cardiac disease and its consequences on the partner relationship: A systematic review. European Journal of Cardiovascular Nursing, 10, 140-149.

DeVellis, R. F. (2012). Scale development (3rd ed.). SAGE Publications, United States of America.

Dolansky, M. A., \& Moore, S. M. (2007). Older adults' early disability following a cardiac event. Western Journal of Nursing Research, 30, 163-180.

Dolansky, M. A, \& Moore, S. M. (2008). Older adults' use of postacute and cardiac rehabilitation services after hospitalization for a cardiac event. Rehabilitation Nursing, 33, 73-81. 
DuBenske, L. L., Gustafson, D. H., Shaw, B. R., \& Cleary J. F. (2010). Web-based cancer communication and decision making systems: Connecting patients, caregivers, and clinicians for improved health outcomes. Medical Decision Making, 30, 732-744.

Entwistle, W. A., \& Watt, I. S. (2006). Patient involvement in treatment decision-making: The case for a broader conceptual framework. Patient Education and Counseling, 63, 268278.

Eriksson, M., Asplund, K., \& Svedlund, M. (2010). Couples' thoughts about and expectations of their future life after the patient's hospital discharge following acute myocardial infarction. Journal of Clinical Nursing, 19, 3485-3493.

Finnish Heart Association. Coronary Artery Disease. Retrieved from http://www.sydan.fi/sydansairaudet-ja-hoito/sepelvaltimotauti. Accessed 21 March 2017.

Ghezeljeh, T. N., Momtahen, M., Tessma, M. K., Nikravesh, M. Y., Ekman, I., \& Emami, A. (2010). Gender specific variations in the description, intensity and location of Angina Pectoris: A cross-sectional study. International Journal of Nursing Studies, 47, 965974.

Hagan, N. A., Botti, M. A., \& Watts, R. J. (2007). Financial, family, and social factors impacting on cardiac rehabilitation attendance. Heart \& Lung, 36, 105-113.

Hammel, J., Magasi, S., Heinemann, A., Whiteneck, G., Bogner, J., \& Rodriguez, E. (2008). What does participation mean? An insider perspective from people with disabilities. Disability \& Rehabilitation, 30, 1445-1460.

Janssen, V., De Gucht, V., van Exel, H. \& Maas, S. (2012). Changes in Illness Perceptions and Quality of Life During Participation in Cardiac Rehabilitation. International Journal of Behavioral Medicine 20, 582-589. DOI 10.1007/s12529-012-9260-3 
Kärner, A., Dahlgren, M. A., \& Bergdahl, B. (2004). Rehabilitation after coronary heart disease: spouses' views of support. Journal of Advanced Nursing, 46, 204-11.

Knoll, S. M., \& Johnson, J. (2000). Uncertainty and expectations: taking care of a cardiac surgery patient at home. Journal of Cardiovascular Nursing, 14, 64-75.

Koivula, M., Paunonen-Ilmonen, M., Tarkka, M. T., Tarkka, M., \& Laippala, P. (2002). Social support and its relation to fear and anxiety in patients awaiting coronary artery bypass grafting. Journal of Clinical Nursing, 11, 622-633.

Kraus, W. E., \& Keteyian, S. J. (2007). Cardiac rehabilitation. New Jersey: Humana Press.

Kärner Köhler, A., Nilsson, S., Jaarsma, T. \& Tingström P. (2017). Health beliefs about lifestyle habits differ between patients and spouses 1 year after a cardiac event - a qualitative analysis based on the Health Belief Model. Scandinavian Journal of Caring Sciences 31, 332-341. DOI: 10.1111/scs.1235

Levy, P. S., \& Lemeshow, S. (1991). Sampling of populations: Methods and applications. Wiley Series in Probability and Mathematical Statistics. John Wiley \& Sons, Inc.

Lie, I., Bunch, EH., Smeby, NA., Arnesen, H., \& Hamilton G. (2012). Patients' experiences with symptoms and needs in the early rehabilitation phase after coronary artery bypass grafting. European Journal of Cardiovascular Nursing, 11, 14-24.

Lukkarinen, H., \& Kyngäs, H. (2003). Experiences of the onset of coronary artery disease in a spouse. European Journal of Cardiovascular Nursing, 2, 189-194.

Luttik, MLA., Goossens, E., Ågren, S., Jaarsma, T., Mårtensson, J., Thompson, DR., Moons, P. \& Strömberg, A. (2017). Attitudes of nurses towards family involvement in the care for patients with cardiovascular diseases. European Journal of Cardiovascular Nursing 16, 299-308.

Mahrer-Imhof, R., Hoffmann, A., \& Froelicher, E. S. (2007). Impact of cardiac disease on couples' relationships. Journal of Advanced Nursing, 57, 513-521. 
Munro, B. H. (2005). Statistical methods for health care research. Philadelphia: J. B. Lippincott \& Co.

Murray, J. C., O'Farrel, P., \& Huston, P. (2000). The experiences of women with heart disease: What are their needs? Revue Canadienne de Sante Publique, 91, 98-102.

Olding, M., McMillan, S. E., Reeves, S., Schmitt, M. H., Puntillo, K., \& Kitto, S. (2016). Patient and family involvement in adult critical and intensive care settings: a scoping review. Health Expectations, 19, 1183-1202.

Palonen, M., Kaunonen, M., \& Åstedt-Kurki, P. (2016). Family involvement in emergency department discharge education for older people. Journal of Clinical Nursing, 25, 3333-3344. doi:10.1111/jocn.13399

Piepoli MF, Hoes AW, Agewall S, et al. 2016 European Guidelines on cardiovascular disease prevention in clinical practice. The Sixth Joint Task Force of the European Society of Cardiology and Other Societies on Cardiovascular Disease Prevention in Clinical Practice. European Heart Journal 37, 2315-2381.

Pryor, T., Page, K., Patsamanis, H. \& Jolly, KA. (2013). Investigating support needs for people living with heart disease. Journal of Clinical Nursing, 23, 166-172.

Rantanen, A., Kaunonen, M., Sintonen, H., Koivisto, A-M., Åstedt-Kurki, P., \& Tarkka, M-T. (2008). Factors associated with health-related quality of life in patients and significant others one month after coronary artery bypass grafting. Journal of Clinical Nursing, $17,1742-53$.

Rebar, C., Gersch, C., Macnee, C., \& McCabe, S. (2011). Understanding nursing research. Using research in evidence-based practice. Philadelphia: Wolters Kluwer.

Rolley, J., \& Thompson, D. (2012). Cardiovascular disease: is it time to finally recognise it as a complex, chronic life-span illness? European Journal of Cardiovascular Nursing, $11,135-137$. 
Roohafza, H., Sadeghi, M., Khani, A., Andali, G. E., Alikhasi, H., \& Rafiei, M. (2015). Psychological state in patients undergoing coronary artery bypass grafting surgery or percutaneous coronary intervention and their spouses. International Journal of Nursing Practice, 21, 214-220.

Roos, M., Rantanen, A., \& Koivula, M. (2012). Sepelvaltimotautipotilaiden terveyteen liittyvä elämänlaatu ja perheeltä saatu sosiaalinen tuki. (Health-related quality of life and social support from family members in patients with coronary artery disease.) Hoitotiede (Journal of Nursing Science), 24, 189-200.

Salminen-Tuomaala, M. (2013). Sydäninfarktipotilaan ja hänen puolisonsa selviytyminen prosessina; Psykososiaaliseen tasapainoon pyrkiminen (Coping of myocardial infarction patients and their spouses as a process; Striving towards psychosocial balance). Academic dissertation. Acta Universitatis Tamperensis 1844.Tampere University Press.

Shepherd, C. W., \& While, A. E. (2012). Cardiac rehabilitation and quality of life: A systematic review. International Journal of Nursing Studies, 49, 755-771.

Stewart, M., Davidson, K., Meade, D., Hirth, A., \& Makrides, L. (2000). Myocardial infarction: Survivors' and spouses' stress, coping, and support. Journal of Advanced Nursing, 31, 1351-1360.

The Social Insurance Institution of Finland KELA. Rehabilitation. Retrieved from http://www.kela.fi/web/en/rehabilitation Accessed 29 August, 2017.

THL (National Institute for Health and Welfare) (2015). Coronary Heart Events. Retrieved from https://www.thl.fi/fi/web/kansantaudit/sydan-ja-verisuonitaudit/sydan-javerisuonitautirekisteri/sepelvaltimotauti/raakaluvut\#Sairaalahoitojaksojen ja hoitopäivien lukumäärät. Accessed 21 March, 2017. 
Tuomisto, S., Koivula, M. \& Joronen, K. (2014). Esitutkimuksen merkitys uuden mittarin tutkimuskäytölle (The meaning of a pilot study for the use of a new scale in research POSEK scale as an example). Esimerkkinä POSEK-mittari. Hoitotiede (Journal of Nursing Science), 26, 136-146.

Vedanthan, R., Bansilal, S., Soto., AV., Kovacic, JC, Latina, J., Jascow, R., Santana, M., Gorga, E., Kasarskis, A., Hajjar, R., Schadt, EE., Björkegren, JL., Fayad, ZA. \& Fuster, V. 2016. Family-Based Approaches to Cardiovascular Health Promotion. Journal of the American College of Cardiology, 14, 1725-1737.

WMA Declaration of Helsinki - Ethical Principles for Medical Research Involving Human Subjects. Retrieved from http://www.wma.net/en/30publications/10policies/b3/index.html.pdf?print-mediatype\&footer-right=[page]/[toPage. Accessed 15 February, 2017.

World Health Organization (WHO) (2016). Cardiovascular diseases. Retrieved from http://www.who.int/mediacentre/factsheets/fs317/en/. Accessed 15 February, 2017.

Åstedt-Kurki, P., Tarkka, M-T., Paavilainen, E., \& Lehti, K. (2002). Development and testing of a family nursing scale. Western Journal of Nursing Research, 24, 567-579.

Åstedt-Kurki, P., Lehti, K., Tarkka, M-T., \& Paavilainen, E. (2004). Determinants of perceived health in families of patients with heart disease. Journal of Advanced Nursing, 48, 115-213. 
Table I. Demographic characteristics and history of CAD and its treatment $(n=169)$.

\begin{tabular}{|c|c|c|}
\hline Demographic characteristics & $\mathbf{n}$ & $\%$ \\
\hline \multicolumn{3}{|l|}{ Gender } \\
\hline Male & 129 & 76 \\
\hline Female & 40 & 24 \\
\hline \multicolumn{3}{|l|}{ Age } \\
\hline 60 years or less & 40 & 24 \\
\hline 61-74years & 93 & 55 \\
\hline 75 years or more & 36 & 21 \\
\hline \multicolumn{3}{|l|}{ Marital Status } \\
\hline Married & 141 & 83 \\
\hline Cohabiting & 13 & 8 \\
\hline Without a relationship & 15 & 9 \\
\hline \multicolumn{3}{|l|}{ Spouse's working status $\dagger$} \\
\hline Working & 40 & 24 \\
\hline Retired & 111 & 66 \\
\hline Not working ${ }^{\dagger}$ & 6 & 4 \\
\hline Missing & 12 & 6 \\
\hline \multicolumn{3}{|l|}{ Family relations } \\
\hline Close relationship & 125 & 74 \\
\hline Quite close relationship & 38 & 22,5 \\
\hline Not close relationship & 5 & 3 \\
\hline Missing & 1 & 0.5 \\
\hline \multicolumn{3}{|l|}{ Economic situation before illness } \\
\hline Meager & 15 & 9 \\
\hline Moderate & 86 & 51 \\
\hline Good/Excellent & 68 & 40 \\
\hline \multicolumn{3}{|l|}{ History of CAD and its treatment } \\
\hline \multicolumn{3}{|l|}{ Onset of symptoms } \\
\hline$>10$ years ago & 34 & 20 \\
\hline 4-9 years ago & 45 & 27 \\
\hline$<3$ years ago & 82 & 48 \\
\hline Missing & 8 & 5 \\
\hline \multicolumn{3}{|l|}{ Appearance of heart symptoms } \\
\hline not even at rest & 56 & 33 \\
\hline with minor exertion & 39 & 23 \\
\hline with heavy exertion & 43 & 25 \\
\hline also at rest & 25 & 15 \\
\hline missing & 6 & 4 \\
\hline Earlier chestpain treatments in hospital & 103 & 61 \\
\hline Myocardial infarction & 72 & 43 \\
\hline Thrombolytic therapy & 22 & 13 \\
\hline Angiography & 163 & 96 \\
\hline PCI* & 126 & 75 \\
\hline CABG* & 18 & 11 \\
\hline
\end{tabular}

*PCI=Percutaneous Coronary Intervention, $\mathrm{CABG}=$ Coronary Artery Bypass Grafting

$\dagger=$ Patients who lost their partners still responded to the question, which causes higher values than in the previous question. 
Table II. Descriptive statistics and internal consistency of the FIRE scale (Cronbach's alpha) $(n=169)$.

\begin{tabular}{|c|c|c|c|c|c|c|c|}
\hline & $\begin{array}{l}\text { Number } \\
\text { of Items }\end{array}$ & $\begin{array}{l}\text { Possible } \\
\text { range }\end{array}$ & Min & Max & $\operatorname{Mean}(S D)$ & Median & $\alpha$ \\
\hline $\begin{array}{l}\text { Family promoting } \\
\text { rehabilitation }\end{array}$ & 16 & $16-96$ & 36 & 96 & $81.3(11.9)$ & 82 & .933 \\
\hline $\begin{array}{l}\text { Enabling good } \\
\text { circumstances }\end{array}$ & 4 & $4-24$ & 5 & 24 & $19.6(3.5)$ & 20 & .763 \\
\hline Family closeness & 4 & $4-24$ & 9 & 24 & $21.1(3.0)$ & 21 & .841 \\
\hline Family member as a carer & 4 & $4-24$ & 7 & 24 & $20.0(3.8)$ & 21 & .885 \\
\hline Motivating patient & 4 & $4-24$ & 9 & 24 & $20.6(3.2)$ & 21 & .758 \\
\hline $\begin{array}{l}\text { Issues encumbering } \\
\text { rehabilitation in family* }\end{array}$ & 30 & $30-180$ & 30 & 145 & $82.5(22.9)$ & 82 & .930 \\
\hline $\begin{array}{l}\text { Future uncertainty } \\
\text { Inadequate support from }\end{array}$ & 4 & $4-24$ & 4 & 22 & $11.1(3.9)$ & 11 & .617 \\
\hline nursing staff & 4 & $4-24$ & 4 & 21 & $9.9(4.3)$ & 9 & .855 \\
\hline Processing emotions & 4 & $4-24$ & 4 & 22 & $12.4(3.8)$ & 13 & .681 \\
\hline $\begin{array}{l}\text { Family's coping with } \\
\text { everyday life }\end{array}$ & 9 & $9-54$ & 9 & 48 & $25.7(7.7)$ & 25 & .834 \\
\hline Family interaction & 5 & $5-30$ & 5 & 28 & $13.2(4.9)$ & 12 & .792 \\
\hline $\begin{array}{l}\text { Family responsibilities for } \\
\text { the patient }\end{array}$ & 4 & $4-24$ & 4 & 21 & $10.1(3.9)$ & 10 & .779 \\
\hline
\end{tabular}


Table III. Associations between family promoting rehabilitation and demographic characteristics $(n=169)$.

Family promoting rehabilitation

\begin{tabular}{|c|c|c|c|c|c|c|c|c|c|}
\hline \multirow[t]{2}{*}{ Background variable } & \multirow[b]{2}{*}{$\mathbf{n}$} & \multicolumn{2}{|c|}{ Enabling good circumstances } & \multicolumn{2}{|l|}{ Family closeness } & \multicolumn{2}{|l|}{ Family member as a carer } & \multicolumn{2}{|l|}{ Motivating patient } \\
\hline & & Md (Q1/Q3) & p & Md (Q1/Q3) & p & Md (Q1/Q3) & p & Md (Q1/Q3) & p \\
\hline Age & & & .822 & & .379 & & .675 & & .531 \\
\hline 1) 60 years or less & 40 & $20.0(19.0 / 22.0)$ & & $22.0(20.0 / 24.0)$ & & $20.0(19.0 / 23.0)$ & & $20.5(18.5 / 24.0)$ & \\
\hline 2)61-74years & 93 & $20.0(17.5 / 23.0)$ & & $22.0(20.0 / 24.0)$ & & $21.0(19.0 / 23.0)$ & & $21.0(19.0 / 23.0)$ & \\
\hline 3) 75 years or more & 36 & $20.0(19.0 / 22.0)$ & & $20.0(20.0 / 23.5)$ & & $20.0(18.0 / 22.0)$ & & $21.0(18.0 / 22.0)$ & \\
\hline Gender & & & .848 & & .782 & & .196 & & .962 \\
\hline 1)Male & 129 & $20.0(18.0 / 22.0)$ & & $21.0(20.0 / 24.0)$ & & $21.0(19.0 / 23.0)$ & & $21.0(19.0 / 23.0)$ & \\
\hline 2)Female & 40 & $20.0(18.0 / 21.5)$ & & $22.0(20.0 / 24.0)$ & & $20.0(16.5 / 22.0)$ & & $21.0(19.0 / 23.0)$ & \\
\hline Marital status & & & .026 & & .126 & & .424 & & .212 \\
\hline 1)Married & 141 & $20.0(18.0 / 23.0) 1>3 * *$ & & $22.0(20.0 / 24.0)$ & & $21.0(19.0 / 23.0)$ & & $20.0(19.0 / 23.0)$ & \\
\hline 2)Cohabiting & 13 & $21.0(19.0 / 23.0)$ & & $21.0(20.0 / 23.0)$ & & $21.0(17.0 / 22.0)$ & & $22.0(21.0 / 24.0)$ & \\
\hline 3)Without relationship & 15 & $18.5(15.0 / 20.0)$ & & $20.0(17.5 / 23.5)$ & & $19.0(16.5 / 22.5)$ & & $22.0(20.0 / 24.0)$ & \\
\hline Spouse's working status & & & .759 & & .845 & & .200 & & .256 \\
\hline 1)Working & 40 & $20.0(18.5 / 22.0)$ & & $22.0(20.0 / 24.0)$ & & $20.0(18.5 / 22.0)$ & & $20.0(18.0 / 23.0)$ & \\
\hline 2)Not working & 117 & $20.0(18.0 / 23.0)$ & & $22.0(20.0 / 24.0)$ & & $21.0(19.0 / 23.0)$ & & $21.0(19.0 / 23.0)$ & \\
\hline Family relations & & & .004 & & $<.001$ & & .001 & & $<.001$ \\
\hline 1)Close & 125 & $20.0(18.0 / 23.0) 1>2 * *$ & & $22.0(20.0 / 24.0) 1>2 * * *$ & & $21.0(19.0 / 23.0) 1>2 * * *$ & & $22.0(20.0 / 24.0) 1>2 * * *$ & \\
\hline 2)Quite close & 38 & $19.0(18.0 / 20.0)$ & & $20.0(18.0 / 22.0)$ & & $19.0(17.0 / 21.0)$ & & $20.0(17.0 / 21.0)$ & \\
\hline 3) Not close & 5 & $19.0(12.0 / 19.0)$ & & $18.0(13.0 / 21.0)$ & & $19.0(8.0 / 21.0)$ & & $17.0(12.0 / 20.0)$ & \\
\hline Economic situation before illness & & & .290 & & .244 & & .458 & & .936 \\
\hline 1)Meager & 15 & $19.0(16.0 / 20.0)$ & & $20.0(18.0 / 23.5)$ & & $19.0(18.0 / 21.5)$ & & $20.5(17.0 / 24.0)$ & \\
\hline 2)Moderate & 86 & $20.0(18.0 / 23.0)$ & & $21.0(20.0 / 24.0)$ & & $20.5(18.0 / 23.0)$ & & $21.0(19.0 / 24.0)$ & \\
\hline 3)Good/excellent & 68 & $20.0(18.0 / 22.5)$ & & $22.0(20.0 / 24.0)$ & & $21.0(19.0 / 22.0)$ & & $21.0(19.0 / 23.0)$ & \\
\hline
\end{tabular}


Table IV a. Associations between issues encumbering rehabilitation in family and demographic characteristics $(n=169)$.

\begin{tabular}{|c|c|c|c|c|c|c|c|c|c|c|c|c|}
\hline \multirow{3}{*}{ Background variable } & \multicolumn{12}{|c|}{ Issues encumbering rehabilitation in family ${ }^{\dagger}$} \\
\hline & \multicolumn{2}{|c|}{ Future uncertainty } & \multicolumn{2}{|c|}{$\begin{array}{l}\text { Inadequate support from } \\
\text { nursing staff }\end{array}$} & \multicolumn{2}{|c|}{ Prosessing emotions } & \multicolumn{2}{|c|}{$\begin{array}{l}\text { Family's coping with } \\
\text { everyday life }\end{array}$} & \multicolumn{2}{|l|}{ Family interaction } & \multicolumn{2}{|c|}{$\begin{array}{l}\text { Family responsibilities for the } \\
\text { patient }\end{array}$} \\
\hline & Md (Q1/Q3) & $\mathbf{p}$ & Md (Q1/Q3) & $\mathbf{p}$ & M (SD) & p & $\mathbf{M}(\mathbf{S D})$ & $\mathbf{p}$ & Md (Q1/Q3) & $\mathbf{p}$ & Md (Q1/Q3) & $\mathbf{p}$ \\
\hline Age & & .609 & & .687 & & .064 & & .201 & & .981 & & .571 \\
\hline 1) 60 years or less & $11.0(8.0 / 13.5)$ & & $8.5(7.0 / 12.0)$ & & $13.4(2.6)$ & & $27.5(6.9)$ & & $12.5(10.0 / 16.0)$ & & $9.0(7.5 / 11.5)$ & \\
\hline 2)61-74years & $11.0(8.5 / 14.0)$ & & $8.0(7.0 / 13.0)$ & & $12.4(4.1)$ & & $25.4(8.2)$ & & $12.0(10.0 / 17.0)$ & & $10.0(8.0 / 13.0)$ & \\
\hline 3)75 years or more & $11.5(8.0 / 14.5)$ & & $9.0(8.0 / 13.5)$ & & $11.5(4.1)$ & & $24.5(7.0)$ & & $13.0(10.0 / 16.0)$ & & $11.0(7.0 / 12.0)$ & \\
\hline Gender & & .362 & & .532 & & .009 & & .077 & & .022 & & .002 \\
\hline 1)Male & $11.0(8.0 / 14.0)$ & & $9.0(7.0 / 13.0)$ & & $12.9(3.8)$ & & $26.3(7.4)$ & & $13.0(10.0 / 17.0)$ & & $10.0(8.0 / 13.0)$ & \\
\hline 2)Female & $11.0(8.0 / 13.0)$ & & $8.0(8.0 / 14.0)$ & & $11.0(3.8)$ & & $23.8(8.3)$ & & $11.0(10.0 / 13.0)$ & & $8.0(6.0 / 10.0)$ & \\
\hline Marital status & & .208 & & .651 & & .032 & & .101 & & .390 & & .025 \\
\hline 1)Married & $11.0(8.0 / 14.0)$ & & $9.0(7.0 / 13.0)$ & & $12.5(3.8)$ & & $26.0(7.7)$ & & $12.0(10.0 / 16.0)$ & & $10.0(8.0 / 13.0) 1>3^{* *}$ & \\
\hline 2)Cohabiting & $10.0(10.0 / 14.0)$ & & $10.0(8.0 / 13.0)$ & & $14.0(3.1) 2>3 *$ & & $26.4(6.9)$ & & $14.0(11.0 / 15.0)$ & & $12.0(9.0 / 13.0)$ & \\
\hline 3)Without relationship & $9.0(8.0 / 12.0)$ & & $8.0(7.0 / 10.0)$ & & $10.2(4.3)$ & & $22.1(7.8)$ & & $11.0(5.5 / 15.0)$ & & $6.0(4.0 / 10.0)$ & \\
\hline $\begin{array}{l}\text { Spouse's working } \\
\text { status }\end{array}$ & & .237 & & .776 & & .204 & & .393 & & .869 & & .210 \\
\hline 1)Working & $10.0(8.0 / 13.5)$ & & $8.5(8.0 / 12.0)$ & & $13.2(3.5)$ & & $26.9(7.5)$ & & $12.0(10.0 / 16.5)$ & & $9.0(8.0 / 11.0)$ & \\
\hline 2)Not working & $11.0(8.5 / 14.0)$ & & $9.0(7.0 / 13.0)$ & & $12.4(3.8)$ & & $25.7(7.5)$ & & $13.0(10.0 / 16.0)$ & & $10.0(8.0 / 13.0)$ & \\
\hline Family relations & & .091 & & .263 & & .089 & & .062 & & $<.001$ & & .196 \\
\hline 1)Close & $11.0(8.0 / 13.5)$ & & $8.0(7.0 / 12.0)$ & & $12.2(3.7)$ & & $25.1(7.0)$ & & $11.0(10.0 / 15.0) 1<3 * *$ & & $9.0(7.0 / 12.0)$ & \\
\hline 2)Quite close & $12.0(9.0 / 15.0)$ & & $11.0(7.0 / 14.0)$ & & $12.6(4.2)$ & & $26.4(9.1)$ & & $16.0(12.0 / 20.0) 1<2 * * *$ & & $10.0(8.0 / 14.0)$ & \\
\hline 3)Not close & $15.0(11.0 / 16.0)$ & & $13.0(9.0 / 14.0)$ & & $15.6(2.3)$ & & $34.0(8.0)$ & & $22.0(18.0 / 23.0)$ & & $10.0(10.0 / 10.0)$ & \\
\hline $\begin{array}{l}\text { Economic situation } \\
\text { before illness }\end{array}$ & & .079 & & .268 & & .957 & & .034 & & .105 & & .361 \\
\hline 1)Meager & $14.0(9.0 / 15.5)$ & & $10.0(6.0 / 14.5)$ & & $12.3(4.8)$ & & $29.9(11.1) 1>3^{*}$ & & $13.0(7.5 / 21.5)$ & & $10.0(5.5 / 15.0)$ & \\
\hline 2)Moderate & $11.0(9.0 / 15.5)$ & & $10.0(7.0 / 14.0)$ & & $12.5(4.0)$ & & $26.2(7.4)$ & & $13.0(11.0 / 18.0)$ & & $10.0(8.0 / 13.0)$ & \\
\hline 3)Good/excellent & $10.0(8.0 / 13.5)$ & & $8.0(7.0 / 11.0)$ & & $12.4(3.5)$ & & $24.1(6.8)$ & & $11.5(10.0 / 15.0)$ & & $9.0(7.0 / 12.0)$ & \\
\hline
\end{tabular}

$\dagger$ Notice the direction of interpretation; the higher the value, the more encumbering issues patients perceive.

${ }^{*} \mathrm{P}<0.05,{ }^{* * \mathrm{P}}<0.01,{ }^{* * * \mathrm{P}}<0.001$ 
Table IVb. Associations between issues encumbering rehabilitation in family and patients' history of CAD ( $n=169)$.

\begin{tabular}{|c|c|c|c|c|c|c|c|c|c|c|c|c|c|}
\hline \multirow{3}{*}{$\begin{array}{l}\text { Background } \\
\text { variable }\end{array}$} & \multicolumn{13}{|c|}{ Issues encumbering rehabilitation in family } \\
\hline & \multirow[b]{2}{*}{$\mathbf{n}$} & \multicolumn{2}{|l|}{$\begin{array}{l}\text { Future } \\
\text { uncertainty }\end{array}$} & \multicolumn{2}{|l|}{$\begin{array}{l}\text { Inadequate } \\
\text { support from } \\
\text { nursing staff }\end{array}$} & \multicolumn{2}{|l|}{$\begin{array}{l}\text { Prosessing } \\
\text { emotions }\end{array}$} & \multicolumn{2}{|l|}{$\begin{array}{l}\text { Family's } \\
\text { coping with } \\
\text { everyday life }\end{array}$} & \multicolumn{2}{|l|}{ Family interaction } & \multicolumn{2}{|l|}{$\begin{array}{l}\text { Family } \\
\text { responsibilities } \\
\text { for the patient }\end{array}$} \\
\hline & & Md (Q1/Q3) & $\mathbf{P}$ & Md (Q1/Q3) & $\mathbf{p}$ & M (SD) & $\mathbf{p}$ & M (SD) & $\mathbf{p}$ & Md (Q1/Q3) & $\mathbf{p}$ & Md (Q1/Q3) & $\mathbf{p}$ \\
\hline Onset of symptoms & & & .057 & & .081 & & .112 & & .608 & & .049 & & .085 \\
\hline 1)>10 years ago & 34 & $13.0(11.0 / 16.0)$ & & $10.0(8.0 / 13.0)$ & & $13.6(3.3)$ & & $27.0(7.0)$ & & $15.0(11.0 / 18.0) 1>3^{*}$ & & $11.5(8.0 / 14.0)$ & \\
\hline 2)4-9 years ago & 45 & $11.0(8.0 / 13.0)$ & & $10.0(8.0 / 14.0)$ & & $11.9(3.8)$ & & $25.4(7.4)$ & & $12.0(9.0 / 17.0)$ & & $8.5(7.0 / 13.0)$ & \\
\hline 3)<3 years ago & 82 & $11.0(8.0 / 14.0)$ & & $8.0(6.0 / 13.0)$ & & $12.3(4.0)$ & & $25.5(8.2)$ & & $12.0(10.0 / 15.0)$ & & $9.0(8.0 / 12.0)$ & \\
\hline $\begin{array}{l}\text { Appearance of } \\
\text { heart symptoms }\end{array}$ & & & .512 & & .053 & & .061 & & .035 & & .387 & & .153 \\
\hline 1)not even at rest & 56 & $10.0(8.0 / 14.0)$ & & $8.0(6.0 / 13.0)$ & & $11.6(4.2)$ & & $23.6(8.4) 1<4^{*}$ & & $11.5(9.5 / 16.0)$ & & $9.0(5.5 / 13.0)$ & \\
\hline $\begin{array}{l}\text { 2)with minor } \\
\text { exertion }\end{array}$ & 39 & $12.0(9.0 / 14.0)$ & & $11.0(8.0 / 14.0)$ & & $12.4(4.3)$ & & $26.8(6.7)$ & & $13.0(10.0 / 16.0)$ & & $10.5(8.0 / 13.0)$ & \\
\hline $\begin{array}{l}\text { 3)with heavy } \\
\text { exertion }\end{array}$ & 43 & $11.0(9.0 / 14.0)$ & & $8.0(6.0 / 11.0)$ & & $12.9(3.3)$ & & $26.1(7.5)$ & & $13.0(10.0 / 17.0)$ & & $10.0(8.0 / 12.0)$ & \\
\hline 4)also at rest & 25 & $11.0(9.0 / 15.0)$ & & $10.0(7.0 / 15.0)$ & & $14.0(3.1)$ & & $28.6(6.9)$ & & $14.0(11.0 / 18.0)$ & & $10.0(8.0 / 13.5)$ & \\
\hline $\begin{array}{l}\text { Chest pain } \\
\text { treatment in } \\
\text { hospital }\end{array}$ & & & .606 & & .736 & & .043 & & .275 & & .596 & & .381 \\
\hline 1)yes & 103 & $11.0(9.0 / 14.0)$ & & $8.0(7.0 / 12.5)$ & & $13.0(3.8)$ & & $26.3(7.8)$ & & $13.0(10.0 / 16.0)$ & & $10.0(8.0 / 13.0)$ & \\
\hline 2)no & 61 & $12.0(8.0 / 14.0)$ & & $8.5(6.5 / 13.0)$ & & $11.7(3.8)$ & & $25.0(7.6)$ & & $12.0(10.0 / 16.0)$ & & $9.0(7.0 / 12.0)$ & \\
\hline $\begin{array}{l}\text { Myocardial } \\
\text { infarction }\end{array}$ & & & .866 & & .258 & & .306 & & .160 & & .902 & & .631 \\
\hline 1)yes & 72 & $11.0(8.0 / 14.0)$ & & $8.0(6.0 / 13.0)$ & & $12.8(3.7)$ & & $26.8(8.5)$ & & $12.0(10.0 / 16.0)$ & & $10.0(7.0 / 13.0)$ & \\
\hline 2)no & 88 & $11.0(8.0 / 14.0)$ & & $9.0(7.0 / 13.0)$ & & $12.2(4.0)$ & & $25.0(7.0)$ & & $12.0(10.0 / 17.5)$ & & $9.0(8.0 / 12.0)$ & \\
\hline $\begin{array}{l}\text { Thrombolytic } \\
\text { therapy }\end{array}$ & & & .892 & & .933 & & .389 & & .890 & & .477 & & .331 \\
\hline 1)yes & 22 & $11.0(8.0 / 14.0)$ & & $10.0(5.0 / 14.0)$ & & $13.2(4.1)$ & & $26.2(8.8)$ & & $14.0(11.0 / 16.0)$ & & $10.0(8.0 / 13.0)$ & \\
\hline 2)no & 128 & $11.0(8.0 / 14.0)$ & & $8.0(7.0 / 13.0)$ & & $12.4(3.8)$ & & $25.9(7.4)$ & & $12.0(10.0 / 16.0)$ & & $9.0(8.0 / 13.0)$ & \\
\hline Angiography & & & .829 & & .432 & & .631 & & .269 & & .920 & & .381 \\
\hline 1)yes & 163 & $11.0(8.0 / 14.0)$ & & $9.0(7.0 / 13.0)$ & & $12.5(3.8)$ & & $25.9(7.7)$ & & $12.0(10.0 / 16.0)$ & & $10.0(8.0 / 13.0)$ & \\
\hline 2)no & 3 & $12.0(10.5 / 12.5)$ & & $8.0(7.0 / 8.5)$ & & $11.6(2.5)$ & & $21.7(4.0)$ & & $12.0(11.0 / 15.0)$ & & $6.0(6.0 / 9.5)$ & \\
\hline PCI & & & $<.001$ & & .004 & & $<.001$ & & $<.001$ & & $<.001$ & & $<.001$ \\
\hline 1)yes & 126 & $10.0(8.0 / 13.0)$ & & $8.0(6.0 / 11.0)$ & & $11.8(3.8)$ & & $24.4(7.8)$ & & $12.0(10.0 / 15.0)$ & & $9.0(7.0 / 11.0)$ & \\
\hline 2)no & 38 & $13.0(11.0 / 15.0)$ & & $12.0(8.0 / 14.0)$ & & $14.4(3.5)$ & & $29.5(6.1)$ & & $16.0(11.0 / 20.0)$ & & $13.0(9.0 / 15.0)$ & \\
\hline
\end{tabular}


CABG:

1)yes

$18 \quad 14.0(11.0 / 16.0)$

.008

$11.5(9.0 / 16.0)$

$8.0(7.0 / 13.0)$

.025

$138 \quad 11.0(8.0 / 14.0)$

.006

$28.7(7.8)$

25.4 (7.6)

.121

$16.5(12.0 / 19.0)$

$12.0(10.0 / 16.0)$

.011

$12.5(11.0 / 16.0$

$9.0(8.0 / 12.0)$

$\dagger$ Notice the direction of interpretation; the higher the value, the more encumbering issues patients perceive.

$\ddagger$ PCI=Percutaneous Coronary Intervention, CABG=Coronary Artery Bypass Grafting.

$* \mathrm{P}<0.05, * * \mathrm{P}<0.01, * * * \mathrm{P}<0$ 